\title{
LINGUAGEM E SENTIDOS DA SUBJETIVIDADE HUMANA EM NARRATIVAS DA CULTURA URBANA: UMA ANÁLISE AOS AUTOCOLANTES USADOS NOS CARROS
}

\author{
Felipe Gustsack \& Sandra Maria de Castro Rocha
}

\begin{abstract}
Resumo
Neste texto problematizamos a prática cultural do ato do próprio sujeito se narrar no contexto urbano, partindo de conceções sobre a linguagem, as tecnologias urbanas e as narrativas realizadas nas interações da vida quotidiana. Apresentamos uma análise das observações recolhidas numa investigação realizada na cidade de Santa Maria - RS - BR, envolvendo recolha e análise de imagens e conversas com condutores de veículos e leitores dos autocolantes de carros, popularmente conhecidos como 'stickers da família feliz'. Entre outras conclusões, verificamos que os autocolantes da "família feliz", colocados estrategicamente nos parachoques dos carros, instigam vários processos de significação elucidativos de formas individuais e coletivas de narrativa auto e hétero identitária, em contexto urbano.
\end{abstract}

\section{Palavras-chave}

Linguagem; cultura urbana; narrativa; família

\section{INTRODUÇÃo}

Desde os tempos em que as paredes das cavernas serviam para registar mitos, leis e demais acontecimentos, existem narradores e, consequentemente, leitores e interpretadores que encontram em meios e materiais diversos, a possibilidade de serem interpretados pelos componentes das suas culturas. Nas palavras de Barthes, sob quase infinitas formas, "a narrativa está presente em todos os tempos, em todos os lugares, em todas as sociedades; a narrativa começa com a própria história da humanidade; não há em parte alguma povo algum sem narrativa; todas as classes, todos os grupos humanos têm suas narrativas, e, frequentemente, estas narrativas são apreciadas em comum por homens de culturas diferentes, e mesmo opostas" (Barthes, 2008, p. 19). As culturas que deixaram legados estruturantes para as sociedades futuras.

A história documenta que cada cultura encontra, através dos recursos e objetos que domina, a sua forma de narrar-se e, assim, perpetuar-se ao longo dos tempos. Acontece assim desde o tempo em que as paredes das cavernas serviam para registar acontecimentos marcantes das comunidades, até aos nossos dias. Identificamos narrativas marcadas por diferentes culturas como a dos egípcios, os feitos faraónicos contados em papiros, os baixos-relevos, as pinturas, assim como as tapeçarias, os mosaicos e iluminuras, através das quais os cristãos medievos contavam suas histórias. Ora, estas formas de narração encontram paralelo em vários fenómenos hodiernos, como os que quotidianamente nos surgem narrados nas traseiras dos carros e que marcam as 
culturas urbanas do presente. Assim, perguntamo-nos: são essas imagens ilustrações de narrativas ou, também, a própria narrativa, trazendo ênfases da história daquele que se narra? Será que essas narrativas que circulam nos carros à nossa frente, não se configuram como um modo, uma linguagem, uma tecnologia por meio da qual também nos narramos, ao observá-las como sujeitos participantes dessa cultura?

Para problematizarmos estas questões partimos da conceção de que, "como uma imagem, a narrativa põe diante de nossos olhos, nos apresenta, um mundo" (Sodré, 1988 , p. 75). No mesmo sentido, concebemos a linguagem como ação da qual participamos no processo contínuo do devir, modelando a nossa identidade e o mundo em que vivemos. De modo a evidenciar a ação, emoção, interação social e convivência transportadas pela linguagem, Maturana (2002) fala de um "linguajar", compreendendo a linguagem como um agir que se processa em coordenações consensuais em interação. Larrosa (2006) afirma que o que somos capazes de ler num livro é o resultado das nossas disposições anímicas mais profundas. Assim, parafraseando-o, dizemos que o que somos capazes de ler numa imagem (pintura, escultura, desenho, gravura) são as nossas maneiras de narrar, propor e registar interações. Nas suas diferentes possibilidades, as narrativas orais, escritas, imagéticas, entre outras, vêm-nos constituindo e, a partir delas, continuamos a criar outras narrativas.

Uma narrativa visual constitui a possibilidade, a circunstância de estarmos em imagem. Quer dizer, as imagens são narrativas (permeáveis) porque se constituem na interligação entre diversas interpretações, tal como tratado por Echeverría (2006) ao mencionar que não podemos dizer como as coisas realmente são, mas somente podemos dizer como nós as interpretamos e as consideramos. Assim, narrar implica interpretarmo-nos a nós mesmos, pois toda forma de conferir sentido, toda forma de compreensão ou de entendimento pertence à linguagem. Nas palavras de Echeverría (2006, p. 32) "não há um lugar fora da linguagem, a partir do qual possamos observar a nossa existência"; ou seja, a experiência da existência humana realiza-se na e pela linguagem.

Ao lançar um olhar focado no urbano, observamos as tatuagens que marcam as peles, as grafites, as pichações, as demais formas urbanas de comunicação visual que se espalham nas fachadas, nos muros e nos lugares mais oportunos e também nos mais impróprios, na qualidade de telas, suportes de manifestações artísticas, de gritos, de suspiros. Isto é, como linguagens em apelos gráfico-visuais, compreendidos numa noção de quotidiano comunicativo que revela a "dimensão ontológica de realização da vida que se marca pela experiência" (Bretas, 2006, p. 29).

No contexto desta problematização acerca dos modos de narrar-se no quotidiano urbano, o principal objetivo deste artigo é contribuir para uma ampliação das reflexões em torno de narrativas próprias da cultura urbana, a partir da análise dos processos de significação subjacentes aos autocolantes da 'família feliz', colados nas traseiras dos carros. O interesse é, ainda, mostrar que este tipo de narrativa, considerando a sua visibilidade e opacidade, suscita diversos sentidos que apontam para a compreensão que temos a respeito da família e também a respeito dos vários tipos subjetividade que se vão configurando nesta mesma cultura urbana. 


\section{NARRATIVAS URBANAS E CULTURA EM OBSERVAÇÃo}

Observamos um crescente processo de isolamento a que homens e mulheres, em nome da segurança e da proteção, se têm sujeitado, ao manterem-se restritos aos lugares seguros, como os shoppings, os condomínios, os prédios, as casas e, também, os carros, desde que os mantenham fora do convívio, isolados por películas escuras que cobrem os vidros e as travas nas portas e janelas. Na verdade, deixam de olhar para o carro que circula ao lado e pelo qual também não são vistos, pois as películas que os protegem de prováveis agressões, entretanto, tolhem-lhes a presença do olhar do Outro, enquanto trafegam pelos mesmos caminhos em cidades que nem precisam ser grandes para que essas atitudes façam parte do quotidiano.

No que respeita aos critérios de proteção e conforto associados ao que seja uma casa, o carro, ao longo de sua história, diz Araújo (2004), compete com a casa, com a habitação. A autora lembra, ainda, que a casa, ao ser concebida, 'concede' ao próprio carro um espaço exclusivo.

Assim, afirma a pesquisadora:

O automóvel concorre com a casa, sendo, no limite, uma forma de habitação, um espaço que oferece em miniatura, mas consistentemente, as proteções e o conforto da casa, qualquer que este seja. Sem mencionar que, às vezes, para determinadas faixas da sociedade, é a sua única casa, o automóvel fecha o indivíduo ao mundo e, dependendo do seu design e composição, oferece mesmo muitas outras possibilidades que, normalmente, a casa não sugere ou permite. Tudo isto não passaria de uma questão de marketing se este não estivesse tão intimamente ligado às características sociológicas dos indivíduos que idealizam, comparam, adquirem e usam um automóvel. Com efeito, trata-se de enquadrar o automóvel e as possibilidades de mobilidade que este oferece no âmbito de um estilo de vida, isto é, de um conjunto articulado de práticas e de representações que define o modo de estar dos indivíduos em sociedade. (Araújo, 2004, p. 4)

Neste contexto da cultura urbana, os automóveis geram sentimentos de acolhimento e, ao mesmo tempo, de ameaça. Acolhem-nos quando convidam ao diálogo plasmado nas narrativas que produzem durante a sua circulação, através dos seus designs, cores e autocolantes e, assim, remetendo-nos a traços ontológicos que caraterizam a história humana. E ameaçam-nos através das narrativas que decorrem da sua potência mecânica, dos seus ruídos ensurdecedores e de tudo o que carregam de desconhecido, de estranho. Mas, à parte deste sujeito das narrativas, há outro sujeito mais concreto, embora não tão invisível, que faz parte da cultura urbana: o sujeito físico que pode ser acolhedor e, ao mesmo tempo, agressor potencial. Aquele que poderá estar no carro ao lado, na calçada, no semáforo; esse estranho, que já não se importa se no carro ou nas sombras se esconde, é por nós mesmos criado, segundo Bauman (1998), por ser aquele que gera a incerteza, na possibilidade de um encontro feliz e, ao mesmo tempo, que dá origem ao mal-estar, ao nos tornar inseguros e perdidos. Nos carros fechados, a película 
faz parte de estratégias urbanas contemporâneas de anulação deste estranho (ou do estranho em nós mesmos), que nem é mesmo visto (ou se deixa ver) às claras. Nesse sentido, vale lembrar que:

Seguindo as teorias da sociologia do imaginário, podemos discernir uma sociabilidade particular a certas 'contraculturas', ou microgrupos sociais, que incluem o desejo de ser invisível como uma forma de expressão identitária. (Tomás, 2010, p. 165)

Queiroz e Lacerda (2005) enfatizam que o homem e a mulher são, por excelência, seres capazes de processar o sentimento do medo, pois reconhecem a necessidade de segurança como fundamental. Os autores avançam no sentido de considerarem que o medo é um ingrediente importante para a produção social do espaço, figurando como uma estratégia de controlo social e "nesse sentido, não parece nenhum absurdo se falar na existência de uma cultura do medo, em particular na sociedade urbana contemporânea" (Queiroz \& Lacerda, 2005, p. 5). Com a mesma ideia concorda Pastana (2005), dizendo que o medo, associado à criminalidade, está hoje incorporado no modus vivendi das grandes cidades:

Cada vez mais as cidades assumem feições ditadas por uma "arquitetura do medo" - muros altos, cercas em volta das residências, alarmes e sofisticados sistemas de segurança, assim como se verificam outros fenômenos correlatos: crescimento visível das empresas privadas de vigilância, elevada quantidade de armas de fogo em circulação, êxodo de zonas e regiões onde o risco de se transitar sozinho pressupõe-se elevado, além de outros mecanismos de autoproteção. Diante disso, os indivíduos e as instituições moldam seus comportamentos à nova realidade e reorientam-se para conviver com o medo e a insegurança, sob a tensão e a expetativa de serem vítimas de ofensas criminais. (Pastana, 2005, p. 183)

Tais comportamentos explicam-se porque somos seres linguajeiros, seres interpretativos; isto é, vivemos da e na busca de sentidos para o que fazemos e deixamos de fazer, para o que somos e deixamos de ser individualmente e em sociedade. Assim, às vezes, temos dificuldade na busca por segurança porque não consideramos como um legítimo outro (Maturana, 2002) aquele que poderia estar a olhar-nos do carro ao lado e o qual também olharíamos quem sabe por desconhecermos que "o possível ponto de vista do Outro faz falta para manter a coerência de sua (nossa) visão das coisas" (Le Breton, 2009, p. 36). Assim, tendemos a negar esse olhar do Outro, contrariando a possibilidade do acolhimento e procurando, "uma forma de proteção simbólica contra a adversidade, uma superfície protetora, contra a incerteza do mundo" (Le Breton, 2009, p. 38).

Bauman (1998), leitor de Deleuze, explica as caraterísticas do consumo da sociedade na pós-modernidade em função da efemeridade, do imediatismo e da fragilidade dos laços afetivos entre as pessoas, agora ligadas através de "amores líquidos". O autor atenta para o desprezo da alteridade nos indivíduos que vivem esse tempo, essa cultura 
e em que não mais reconhecem o outro em todas as relações, o que causa "bloqueios" à possibilidade quotidiana de comunicação.

Deleuze, citado por Le Breton (2009, p.37), explicita ser pelo Outro que passa o desejo do indivíduo: "o que eu desejo é o que é visto, é pensado, possuído por um possível outro".

Diante disso, e tomando-se uma linha de pensamento que perspetiva como um modo de narrar(-se) também o desejo de isolamento e de ocultar-se na obscuridade provocada pelos vidros dos carros, concebe-se, de outro modo, a ocultação como etapa de um jogo, pois em outros espaços há que dar-se a sua abertura de mundo, em fronteiras por onde se exterioriza recobrando, pela ideia veiculada pelas figuras, o que Guimarães \& França (2006) explicam como sendo o vínculo social. Este constitui-se discursivamente, por um número indeterminado de jogos de linguagem: "Os homens, libertados (ou descrentes) das grandes narrativas se convertem em sujeitos de novas e episódicas enunciações" (Guimarães \& França, 2006, p. 95).

Pensando com Maffesoli (2006), poderíamos remeter-nos à ambígua condição de quem, ao escolher a atitude mais individualista de se proteger que, mesmo levada a termo, tende a dissipar-se em vista da humana necessidade de identificação com um grupo, com uma tribo. No caso presente, pelo menos com a tribo dos que possuem ou cultivam a imagem da sua família nos carros.

Segundo o autor, tais tribos urbanas podem ser compreendidas como redes diversas, que se formam em grupos de afinidades, de interesse e laços de vizinhança que se estabelecem de um modo mais ou menos efémero (Maffesoli, 2005) e comungam de valores minúsculos que se chocam, se atraem e também se repelam "numa constelação de contornos mal definidos e totalmente fluídos" (Maffesolli, 2005, p. 18).

Essa compreensão sobre a comunhão de valores minúsculos aproxima o pensamento de Maffesoli do de Hall, quando este expõe a ideia da existência de uma identidade flexível ou de identidades múltiplas, conceito que define como um "descentramento da identidade fixa e estável, resultando nas identidades abertas, contraditórias, inacabadas, fragmentadas do sujeito pós-moderno" (Hall, 2006, p. 46).

Para que se possa ter uma melhor compreensão dos espaços e da cultura urbana, no que resulta em atenta mobilidade, o desafio dos pensadores e políticos contemporâneos, segundo Bauman (2009), é recuperar a dimensão comunitária do espaço público, como forma de aprender a arte de uma coexistência segura, pacífica e amigável. Procuraremos, assim, prosseguir esta problematização acerca dos modos de interpretar e narrar o espaço urbano, sistematizando informação produzida por meio de observação direta na cidade de Santa Maria - RS - BR.

\section{NotA METODOLÓGICA}

De modo a melhor organizar a produção de dados, foi traçado um plano de observação, mesmo que nossa intenção fosse realizar o que Lakatos e Marconi (1988, p. 170) dizem ser uma observação assistemática, também chamada observação espontânea, 
informal, simples, livre ou ocasional. É a observação sem o emprego de qualquer técnica, sem planeamento, sem controlo e sem requisitos observacionais previamente elaborados. Foi decido que o público-alvo seria formado por ocupantes de carros com autocolantes, mas tal público teve que ser alargado, devido ao interesse de outras pessoas que se aproximavam durante as fases do trabalho, atraídos pelo pitoresco, talvez. A primeira ação planeada para este trabalho foi a produção do registo fotográfico aleatório das imagens coladas aos carros. Escolhemos, para essa fase da pesquisa, atuar em cenários urbanos de mobilidade de carros, quer em circulação, quer estacionados nas ruas, calçadas, escolas, praças, parques de supermercados e de centros comerciais. Algumas imagens também foram recolhidas na Internet, de modo a complementarem o arquivo.

Era, porém, importante levantar indicadores sobre o modo como cada um percebe e significa os autocolantes. No plano traçado, constavam a forma de abordagem dos entrevistados, assim como a intenção de relatar a experiência no presente artigo. $O$ nosso desafio foi agir da maneira mais espontânea possível, aguardando que as pessoas se aproximassem dos carros com os autocolantes. Devido a esse procedimento, não houve seleção prévia, como também se tornou improvável precisar anteriormente o número de participantes, considerando que, ao nos dirigirmos a um membro de uma família, todo o grupo interagia em redor do assunto durante as entrevistas.

A partir das questões de pesquisa, conversamos com 32 pessoas/famílias que produziram algumas narrativas em torno das composições de suas famílias nos respetivos autocolantes. Assim, organizamos as informações propiciadas pelas conversações em seis dimensões sobre as quais falaremos adiante.

\section{VEÍCUlos COMO MEDIA DE DIVULGAÇÃo}

Andando de carro pela cidade - em qualquer cidade brasileira - encontramos inúmeros autocolantes colados nas traseiras dos carros. Isso há muito não é novidade. Deparámo-nos com as folclóricas "frases de camiões" colocadas na parte de trás dos carros e que, por mais hilariantes, grotescas e críticas que aparentassem ser, tinham como função implícita aplacar a solidão das viagens, as dificuldades das estradas. De certa forma, mostravam que quem estava no caminhão da frente tinha, a seu modo, algo a dizer, alguma intencionalidade (Fig. 1). Deste ponto de vista, as frases, assim transportadas pelo espaço urbano e estradas, irradiam sentidos e significados diversos, conforme os sujeitos, o que evidencia a abordagem de Echeverría (2006, p. 42) ao observar "perfeitamente podemos dizer: diz-me o que observas e dir-te-ei quem és", isto é, a leitura feita por um observador fala-nos de quem ele mesmo é, de sua cultura. 


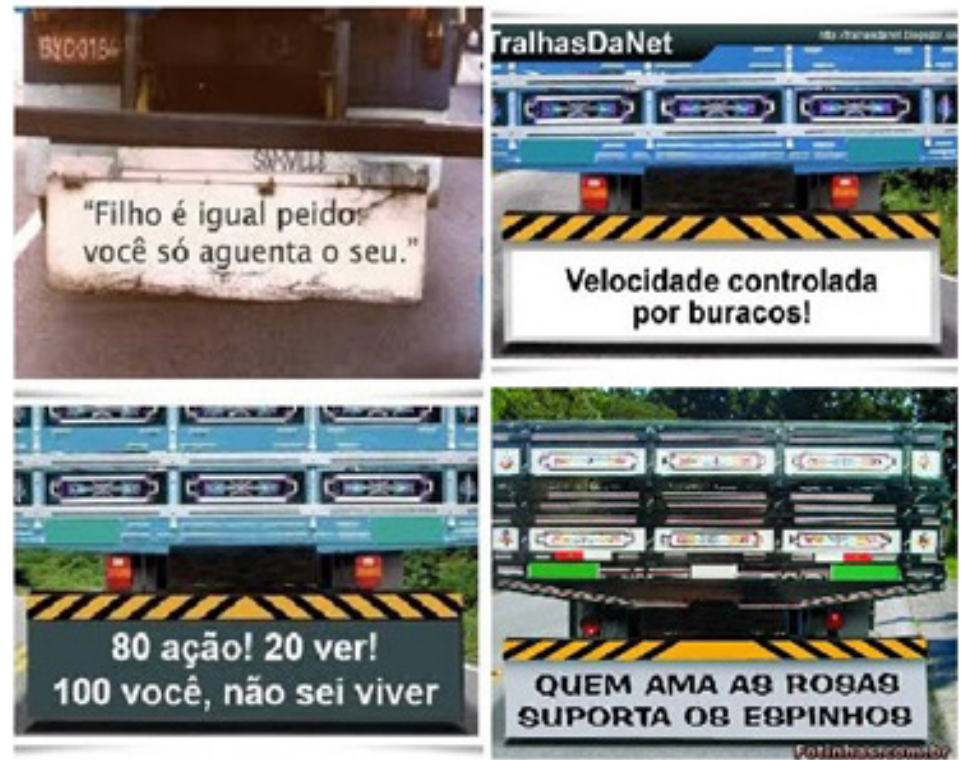

Figura 1: Frases de camiões. Da direita para a esquerda, frase 1, 2, 3 e 4 Fonte: Acesso on line

Hoje, é cada vez mais raro encontrarmos essas frases nos camiões, porque a maioria pertence a frotas empresariais que prezam pela 'limpeza do layout' das carrocerias e tal exige impessoalidade.

Também não é novidade que os carros levam autocolantes de personagens de estórias aos quadrinhos, de artistas e políticos. Não são novidade, igualmente, os carros comerciais "timbrados" com as respetivas mensagens empresariais e publicitárias para as quais se encontram todo tipo de autocolante. Com efeito, essa tecnologia, ao desenvolver - se e ao tornar-se acessível, tanto no que se refere a custos como a ofertas, tem-se constituído como estratégia de marketing de empresas destinadas a promover a fixação de suas marcas. Trata-se de carros com a funcionalidade de serem, para além de veículos locomotores, meios de divulgação.

Nesse espaço de possibilidades visuais oferecidas pelas cidades - e pelas estradas, conforme a saudosista referência aos camiões - emergem diversos processos comunicativos. Adotando preferencialmente a parte posterior dos carros como suporte, os apelos constituem por meio de pedidos de leituras endereçados aos ocupantes do carro de trás (já que com os do carro ao lado a comunicação está dificultada pelo fechamento dos vidros ou pela escuridão das películas).

Uma breve análise semiótica desses materiais mostra-nos que nestas narrativas da cultura urbana exprimem-se gostos, traços pessoais e afetos, não se excluindo escolhas

\footnotetext{
' Frase de camiãol - Acedido em http://2.bp.blogspot.com/-r6ZW-ccG7ik/TZJvtoVo7_I/AAAAAAAAACY/qKsz_IpL5Wg/ s16oo/caminh\% ${ }_{25} \mathrm{C}_{3} \% 25 \mathrm{~A}_{3}$ o.png. 2

Frase de camião 2 - Acedido em https://encrypted-tbn2.google.com/images?q=tbn:ANdgGcTDKKAtBiY4aycRowowoPCg $\mathrm{H}_{3} \mathrm{AcW}$ ngjw3_k4)t_CjLF8525slj/5A. Consultada em 30/07/2015.

Frase de camião3 - Acedido em http://2.bp.blogspot.com/_m315Tl707sk/TFrXvtbDEel/AAAAAAAABJo/XmhS3PXQjlc/ s1600/Frases+caminh\% $\mathrm{C}_{3} \% \mathrm{~A}_{3} 0+08 . j p g$.

Frase de camião 4 - Acedido em https://ensfundamental 1.wordpress.com/frases-de-parachoque-de-caminhao/. Consultada em 30/07/2015.
} 
espirituais, lazeres etc., tal como se demonstra pela série de imagens reproduzidas abaixo (Figura 2).
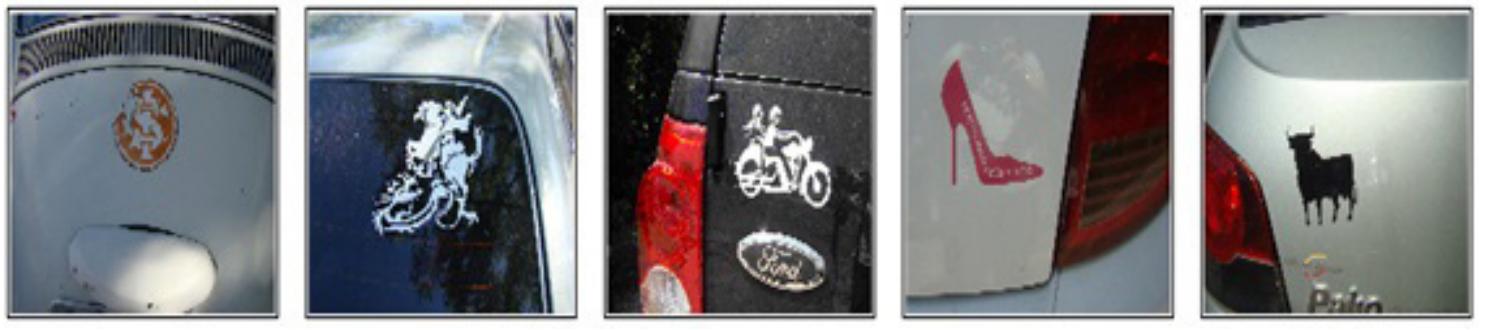

Figura 2: Expressões de gostos, preferências, por meio das figuras

Estas ilustrações constituem formas específicas de comunicação. Uma comunicação que pode ser entendida, no sentido dado por Maffesoli (2006, p. 44), como uma forma sensível da vida social contemporânea, compreendida fora dos imperativos morais, como elo a servir de "cimento social" numa época de crise das velhas certezas e de desabamento das antigas utopias. Nessa linha, podemos dizer que os autocolantes nos carros promovem redes de trocas simbólicas tecidas em mapas afetivos, através dos quais os habitantes dos veículos que vão à frente compartilham o seu campo de vivências e de relações com alguém que vem atrás - ou que vê o carro por trás. Por isso, essas imagens e expressões são signos que solicitam a participação de outros na produção identitária de outro alguém nessa forma que escolheu para narrar-se. Uma pergunta nos ocorre: na impossibilidade de estabelecer formas "convencionais" de comunicação, essa seria uma forma de as pessoas se abrirem ao mundo, de criar fronteiras por onde se deem a ler, já que não se dão a ver? Ou, então, seria essa a disposição para a leitura de si uma forma de dar-se a conhecer?

Ao considerarmos os autocolantes colocados nos carros como narrativas, estamos a tomá-los como sendo propiciadores de estórias, pois é a narrativa que possibilita ao vivido caraterísticas de uma estória. Tais autocolantes, como qualidade de artefacto de uma cultura visual, na possibilidade de ser apreendida pelo olhar do outro, são uma forma de orientar a visão desse outro para que nesse carro "adentre". Estas imagens são composições, são interpretações e, deste modo, autonarrativas poéticas (dos autores e suas famílias). Seriam uma maneira de mostrar ao outro que os habitantes desse carro não são vazios, que têm o que contar, que dão significado a algo? Os autocolantes pegados nos carros particulares repetem a função dos comerciais: servem também de materiais de divulgação? E assim como os outros têm, uma vez que são de natureza comunicativa e visual, a possibilidade de estruturar o sentir e o pensar do leitor?

Tanto as narrativas escritas como as imagéticas instigam a nossa subjetividade. Esta conceção de narrativa abarca possibilidades de uma narrativa da imagem e de uma narrativa por meio dela. O jogo com o observador/leitor acontece na escolha das imagens "eloquentes" com as quais, em interações possíveis, quer se narrar ao mundo.

Debruçamo-nos na nossa pesquisa num primeiro momento, sobre o uso de autocolantes associados à experiência e conceitualização da família. Com o foco nos sticker, 
nas imagens que "tatuam" os automóveis, fomos percebendo a sofisticação de elementos identitários disponibilizados a quem opta colocar essas imagens nos seus carros. A composição de uma 'família feliz' adesivada no carro em frente leva as pessoas a produzir narrativas silenciosas de identificação/diferenciação, de inclusão/exclusão de elementos e características de si e de suas relações como estratégias que as levam a compor a imagem da sua família.

$\mathrm{O}$ adepto do sticker, em interação com imagens, escolhe e cria sua imagem de família, cujos membros adquirem o estatuto de personagens integradas nos dispositivos de narração de si e dos outros, nesse cenário familiar. O observador/leitor interpretará essa imagem, sendo instigado por ela a criar representações e enredos que também se entrelaçam no processo autonarrativo. Ou seja, a narrativa visual constitui, assim, a circunstância e a possibilidade do sujeito apresentar-se, dispor-se a si mesmo em imagem.

As interpretações de imagens, no caso dos stickers, provocam uma interação entre quem escolheu as imagens e quem as observa como leitor. Entre eles, seguindo palavras de Maffesoli (1995, p. 93), a imagem é, antes de tudo, um vetor de comunhão, interessado mais pela emoção que faz compartilhar do que pela mensagem que deve transpor, isto é, a imagem é sedução, seja qual for o seu conteúdo, pois ela favorece um sentir coletivo e um linguajar, ou seja, modos de narrar num dado contexto cultural.

\section{CONSTITUÍMO-NOS NAS NARRATIVAS}

Pelo exposto, é oportuno dar evidência a narrativas dos adeptos dessa prática social, retirando-os da banalidade do quotidiano. Em conversações suscitadas pelos autocolantes que fomos registando durante a observação, pudemos assinalar narrativas de si e do grupo familiar de pertença dos sujeitos.

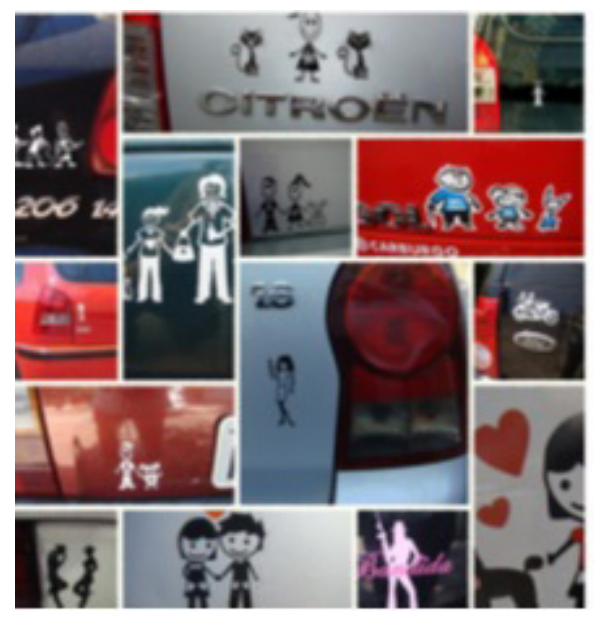

Figura 3 - autocolantes de solteiros

Lembramos que, num primeiro momento, direcionamos o foco para as possíveis narrativas em torno de dimensões familiares. À medida que progredimos na observação, percebemos que essa prática de contar-se em autocolantes nas traseiras dos carros revelava outros contornos. 
Com efeito, além da tradicional família feliz, percebemos que circulavam nos parachoques dos carros, como a se revelar contra as famílias que ocupavam o espaço da narrativa pública, imagens de solteiros de toda a ordem (mulheres, homens, com filho, cachorro, gato; sem filho, sem cachorro, sem gato...) que passaram a reclamar seu lugar nesse linguajar (Figura 3). E, parafraseando Bachelard, com elas reagimos, pois, a partir de uma imagem, ativamos as nossas vivências e podemos construir ressignificações do mundo. Como afirma Bachelard, a imagem 'desperta em nós o ser ativo (Bachelard, 1994, p. 53).

A seguir, apresentamos exemplos dessas narrativas em imagens, tradicionalmente conhecidas como "sticker da família feliz". Abaixo dessas imagens registamos um conjunto mínimo, possível de usar no presente artigo, de argumentos que diferentes integrantes das famílias apresentam acerca de suas escolhas e os quais remetem para os traços culturais que marcam as suas identidades.

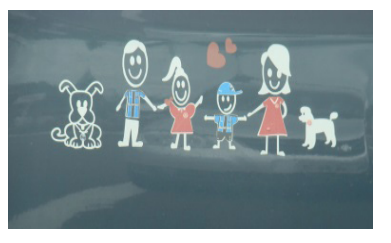

Uma filha:

Na minha família o meu pai e o meu irmão torcem para o Grêmio e eu e a minha mãe p'ro Inter. Eu sou a mais velha. Meu irmão é o "filhinho da mamãe". No dia das mães nós demos uma cadelinha poodle pra ela. Agora o cachorro do pai, que tá bem velho, tem companhia. Quando escolhi o autocolante, quis mostrar que eles cuidam de nós e que somos deles. (Referindo-se aos animais de estimação).
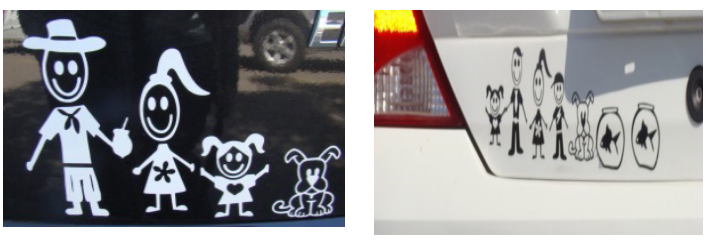

Uma mãe:

Lá em casa, moramos nós três e o cachorrinho do meu filho. Domingo, quando estamos os três em casa, acordamos cedo e tomamos chimarrão junto. Meu marido é chegado em músicas tradicionalistas, na vida campeira. Eu prefiro ficar na cidade, sou da cidade, só vou pra fora pra descansar. No outro carro, nós tínhamos um autocolante com o brasão do Rio Grande do Sul. Agora eu, quando vi esse gaúcho (referindo-se ao autocolante), não resisti e coloquei no carro. Ele disse que não gosta dessas coisas, mas adorou ser chamado de gaúcho num estacionamento de São Paulo, por outro gaúcho.
Um avô:

Quem comprou a figura fui eu, eles colocaram. Aqui, dá pra ver que sou eu, o vô (apontando para a figura), a vó, o filho e a filha e uma neta.

Está ainda faltando outra neta, que nasceu agora em dezembro e o genro, que é gremista, que não quis que colocássemos ele. Aqui ó, tem outro autocolante:

"Nenhum sucesso na vida compensa o fracasso no lar". Eu sou membro da religião [...] e um dos nossos apóstolos colocou isso numa conferência. Não adianta termos sucesso, ganharmos dinheiro e dentro de casa minha família estar desunida. Assim nós não vivemos a felicidade plena.

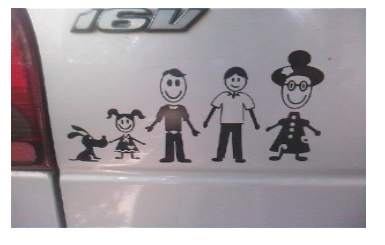

Um "dindo":

Foi muito interessante... ela me dizia há dias que queria colocar a "foto" da nossa família no carro da mãe. Eu saí com ela, fomos até a banca, ela escolheu, escolheu, tinha vários tipos de pessoas. Daí, decidiu que queria colocar assim: o Boby (o cachorrinho dela), ela, o meu irmão (o pai dela), eu (o dindo dela) e a minha mãe (a avó dela). Eu olhei e comecei a rir, porque ela nos colocou lado a lado e, como estou sem namorada e o meu irmão não está mais casado, dá para pensarem que somos um casal gay, com a mãe (com cara de vovó) e a filhinha e o cachorrinho adotados pelo casal.

Tabela 1: Exemplos de narrativas em imagens e argumentos dos familiares

Através da observação das narrativas apresentadas acima, percebemos que nas elaborações das imagens de si, os sujeitos experimentam, com um potencial interlocutor, um exercício político nesse espaço comunicativo que se dá na vida quotidiana. Quando dizem "quis mostrar", " não resisti e coloquei no carro", "Aqui, dá pra ver", "dá para pensarem" sugerem, também, o quanto essa imagem de si passa, necessariamente, pelo reconhecimento da leitura, da presença do outro. 
As nossas experiências permitem reafirmar que a perceção da imagem depende das nossas vivências, das interpretações que fazemos a partir de nós mesmos, das interações com o meio, das ressignificações que fazemos nas linguagens. Estamos continuamente a constituir-nos por meio de diferentes narrativas em diversas dimensões ou tipos de linguagem, num "fluir de coordenações de ações," num linguajar, conforme nos lembra Maturana (2002).

Para Heilbrun (citado em Colomer, 2001, p. 4), "vivemos as nossas próprias vidas através dos textos. Podem ser textos lidos, contados". Comentam os autores que qualquer que seja a forma ou o meio, as histórias vão-nos formando e são elas que devemos usar para produzirmos novas ficções, novas narrativas. Com esses autores, compreendemos que somos seres contadores de histórias e somos organismos que, individual e socialmente, vivemos vidas relatadas.

No desafio de conhecermos alguns relatos de adeptos dos autocolantes, percebemos que os seus autocolantes são colocados nos carros de forma talvez inconsciente, para provocar o próprio momento de se narrarem; como um disparador, um ícone, um link para o que ele se insinua. Seriam um recurso de afetividade, algo como o abrir das janelas do carro para dizer que quem vai lá dentro tem a quem amar e é amado, para dizer-se pessoa do bem, familiar.

A partir das questões de pesquisa conversamos com 32 pessoas/famílias que produziram algumas narrativas em torno das composições de suas famílias nos respetivos autocolantes. Assim, organizamos as informações propiciadas pelas conversações em seis tipos, das quais fizemos os destaques que seguem. Cada um dos tipos está sustentado numa abordagem teórica específica.

\section{NARRATIVA COMO REDE DE CONVERSAÇÕES CRUZADAS}

O relato que segue é resultado do convite dirigido a uma mãe que saía de uma pracinha com seu filho de 3 anos, para se narrarem através do autocolante:

Mãe - [...] mostra todo mundo de mãozinha, ó... tem todo mundo... o time (equipa)... menos a mamãe que não é gremista, mas teve que virar gremista à força...Que mais... O L. de mãozinha com o papai. E aí todo mundo sabe que o papai tem dois gurizinhos gremistas. Sabe... foi no aniversário do papai, nós demos pra o papai esse autocolante de presente.[...] e tem os coraçõezinhos...

Filho - tem o G. (ele), o L. (o irmão). Papai. A mamãe. A N. (irmã).

Aqui se percebe como a narrativa colada no carro, assim como a sua descrição acima relatada, foram constituídas pela observação dos narradores a respeito de si e dos outros. Nessa perspetiva, vale lembrar Maturana (2001, p. 130), quando afirma que "a linguagem acontece quando duas ou mais pessoas operam através de suas interações recorrentes numa rede de conversações cruzadas, recursivas e consensuais". 


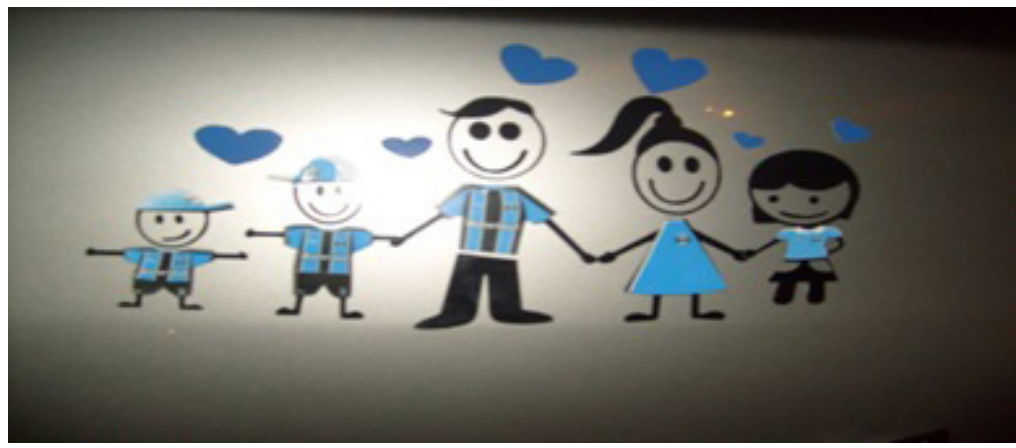

Figura 4: Família gremista feliz - Referência a adeptos do Grêmio Foot-Ball Porto Alegrense

\section{NARRATIVA COMO ATRIbUiÇÃo DE PAPÉIS AOS PERSONAGENS DA VIDA}

Algumas vezes, mesmo sem estarmos diante do carro com o autocolante, as pessoas que desejaram conversar connosco não hesitaram em falar de si. Poderíamos dizer, na base do exemplo abaixo, que até deixam transparecer, pela ordem em que nominam os "familiares," a importância que lhes atribuem. Ao perguntarmos se uma senhora (M.I.) possuía autocolante no carro, ela respondeu assim:

M.I. - Eu tenho... não sou nada contra... Realmente tem muita coisa a ver... pra mim, vale a união. Mas tem gente que é contra [...], mas eu tenho no meu carro... coloquei as duas cachorrinhas, eu, ele (o marido), e o meu gurizinho... que eu só tenho ele...

A espontaneidade da fala deixa transparecer o lugar ocupado pelos "membros" da família, o lugar dos animais, dos filhos, dos cônjuges e de si mesmos numa narrativa. Sem esquecer, ainda, que esses autocolantes são escolhas dos filhos. Tal como viemos a saber vale lembrar que "é a narrativa que faz de nós o próprio personagem de nossa vida; é ela, enfim, que dá uma história a nossa vida: não fazemos a narrativa de nossa vida porque temos uma história; temos uma história porque fazemos a narrativa de nossa vida" (Delory-Momberger, 2008, p. 37).

Outras escolhas, para nossa surpresa, trazem informações bem particulares das relações familiares, o que nos leva a pensar nas linguagens urbanas como aproximativas, que hibridizam as ordens do público e do privado.

\section{NARRATIVA COMO MEMÓRIA DE VÍNCULOS AFETIVOS}

Para ilustrar este tipo usamos a estória de um menino de 4 anos que encontramos com a sua família e a quem perguntamos se tinha autocolante no carro. Imediatamente levou-nos até os carros que estavam estacionados próximos e começou a mostrar-se no autocolante do carro dos seus pais (Figura 5). 


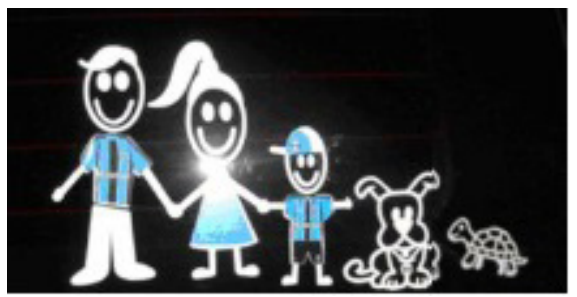

Figura 5 - Ilustração de vínculos afetivos

Ele, a sua tartaruga, o cachorro, a mãe e o pai no carro dos seus avós (o avô, a avó, ele, a prima e a tartaruga). Quando perguntamos quem eram, foi por essa ordem que R. apontou a família e, depois, relatou que tem uma tartaruga "bem pequenininha" e que a prima é filha do tio, "que dá bola para ela, mas a mãe dela nem dá bola para ela" (provavelmente uma interpretação amparada em narrativas adultas da família). Ele queria muito contar essa particularidade, pois voltou no assunto da prima que compunha, com ele, o quadro familiar dos avós. Chamou-nos a atenção a insistência de R. quanto ao registo desse vínculo afetivo. Além disso, a mãe do R. contou-nos que, quando foram comprar o autocolante para atender ao pedido dele, se surpreenderam quando o menino pediu o autocolante do cachorro, pois ele tem um cachorro de peluche.

Trata-se de uma narrativa que evidencia como a família aceitou e resignificou na imagem final as experiências afetivas, ou a memória afetiva da criança, independentemente dos vínculos apontarem para seres vivos ou inanimados. A narrativa produziu aqui um 'sistema' em cujas imagens a criança se identifica. Segundo Bosi (1999), que retoma Bergson, a composição desta narrativa deu-se de maneira similar à descrição do:

Próprio dinamismo interno da memória como um processo que parte de uma imagem qualquer e, por meio de associações de similaridade ou de contiguidade, vai tocando outras imagens que forma com a primeira um sistema. A recordação seria, portanto, uma organização extremamente móvel cujo elemento de base ora é um aspeto, ora outro do passado; daí a diversidade dos 'sistemas' que a memória pode produzir em cada um dos espectadores do mesmo fato. (Bosi, 1999, pp. 50-51)

\section{NARRATIVA COMO PRODUTO DA CULTURA E DA VIDA QUOTIDIANA}

Podemos constatar, através da análise à linguagem dos autocolantes colados nos carros, a prevalência do gosto de crianças e de mulheres na escolha dessas imagens. Mas existem algumas exceções. É o caso de um senhor cujo relato apresentamos abaixo (Figura 6).

E. H. Foi uma briga... Na verdade, foi o P. (filho), porque os coleguinhas dele tinham. $\mathrm{Na}$ escola, os colegas usavam o autocolante, né... no carro dos pais... os pais usavam... e daí ele passou a nos cobrar. Na verdade, nós passamos a observar os autocolantes nos carros. Aquela coisa tipo... olha 
lá... tem mais cachorrinho que... a própria família... a gente começou a ver isso aí... a gente saiu a procurar... Nós procuramos e parece que a coisa tava meio em falta... Aí, depois achamos, nos identificamos com aquilo ali, até por causa do time... nós sermos gremistas, mais o cachorro, gremista também... foi isso aí... ele falou... no começo e nós mesmos ficamos na expectativa, no sentido de ficar observando... tem até coisas criativas... tinha o casal, tantas guriazinhas pra cá, os gurizinhos e uma fila enorme de bichinhos e nós, cuidando..

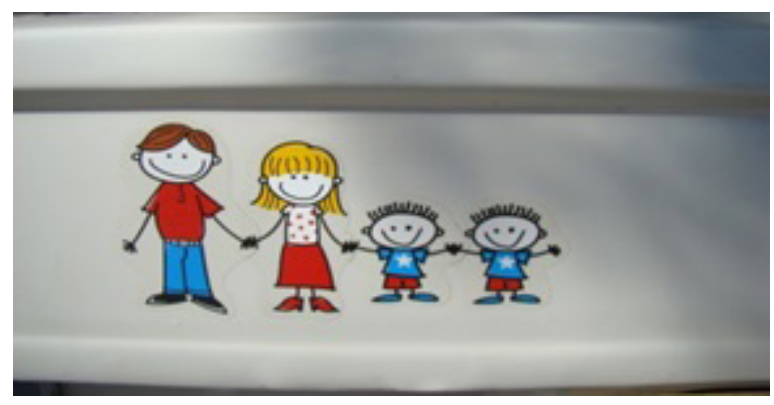

Figura 6- Ilustração da vida quotidiana

Esta narrativa (Figura 6), em comparação com o relato acima transcrito, demonstra como a linguagem que a sustenta, bem como as condições culturais de sua produção, interferem na sua constituição final. Chama a atenção a diferença entre aspetos relatados a respeito do processo de constituição da narrativa e a imagem colada no carro como narrativa final. O relato, que é também uma narrativa (Barthes, 2008), mostra que esta família teve dificuldades em encontrar uma imagem com a qual se identificasse, assim optando por uma versão próxima, definida mais por referência às cores da equipa pela qual torcem os seus membros e à tendência cultural de colocar autocolantes nos carros do que por outra razão. Pode-se dizer que há equívocos quanto à linguagem se comparados os dois textos. Isso não depõe contra à conceção de narrativa, uma vez que os cinco elementos essenciais à sua estrutura estão presentes: o acontecimento, as personagens, o tempo, o espaço e o narrador. Retomando Barthes pode dizer-se que "a narrativa ridiculariza a boa e a má literatura: internacional, transhistórica, transcultural; a narrativa está aí, como a vida" (Barthes, 2008, p. 19).

\section{NARRATIVA COMO ELEMENTO DE PODER}

Num rápido encontro no estacionamento de um shopping, conversamos com uma jovem senhora que ia buscar os filhos. Dirigimo-nos para os meninos que contaram ter sido a mãe quem quis colocar "a família" no carro. Eles gostaram do autocolante, mas não gostaram de não poder colocar as suas "fotos" nas camisetas do grémio, embora as camisetas dos meninos da imagem sejam azuis, porque a mãe não quis. E disseram que ainda estava a faltar colocar o cachorrinho que ganharam, que era muito pequeno. A mãe, piscando um olho para nós, enquanto os meninos entravam no carro, disse que 
ela colocou o autocolante para "todas" (referindo-se às mulheres) saberem que o dono daquele carro é bem casado e tem dois filhos.

Esta narrativa mostra-nos como a sociedade possibilita a atribuição de:

Palavras, maneirismos e grandes frases, rituais de linguagem, à massa anónima do povo para que possa falar de si mesmo - falar publicamente e sob a tripla condição desse discurso ser dirigido e posto a circular no interior de um dispositivo de poder bem definido, de fazer aparecer o fundo até então quase impercetível das existências e de, a partir dessa guerra ínfima das paixões e dos interesses, dar ao poder a possibilidade de uma intervenção soberana. (Foucault, 1992, p. 123).

\section{NARRATIVA COMO DESEJO DE MEMÓRIA}

É caraterística do humano a organização e classificação de eventos de ordem natural, social, política, económica, presentes na circularidade dos fenómenos, no intuito de compreender-se a si e ao meio, atribuindo-lhes significados, ou, como prefere Derrida (2001, p. 9), ao desconstruir o princípio de arquivo com o "mal de arquivo" como a" impaciência absoluta" de um "desejo de memória".

Num outro momento, partilhado com um casal, acompanhado de seu filho, o pai contou-nos de quais e quantos personagens se constituía o autocolante da família deles. No fim, acrescentou: "agora se incorporou mais um peixe na família, o Albert. Não está no carro". E, rindo, afirma: "não está catalogado".

Os sentidos desta narrativa, uma vez mais a partir de Derrida, podem ser ampliados numa comparação entre ficção e realidade. Afinal, ela mostra-nos uma "cumplicidade entre ficção e testemunho". Ou seja, há uma aproximação entre o ficcional e o vivido que é próprio dessa narrativa da cultura urbana e que amplia a conceção de memória para além do registo, para a qual "o testemunho não literário não é mais prova do que é o testemunho na forma de uma ficção literária" (Derrida, citado em Leite, 2009, p. 79).

Se considerarmos os autocolantes que "listam" os componentes da família, a prática de expor a imagem escolhida da família, assim como a multiplicidade das configurações e arranjos através dos quais se mostram, é possível avançarmos no sentido de percebermos uma mudança na constituição 'imaginária' da família, esta agente de abertura à coexistência de diversos modelos.

As imagens coladas nas traseiras dos carros trazem, portanto, antes de mais, imagens de família, construídas pelo grupo a que pertencem quem os transporta. Referimo-nos a todo tipo de imagens: cinematográficas, pictóricas, esculturais, tecnológicas e por aí adiante. Maffesoli (2001) afirmou que não é a imagem que produz o imaginário, mas o contrário. A existência de um imaginário, disse o autor, é o que determina a existência de conjuntos de imagens. E sustentou: "A imagem não é o suporte, mas o resultado" (Maffesoli, 2001, p. 76).

Nesse sentido, ao mesmo tempo que abordamos essas manifestações linguajeiras de colocar autocolantes nos carros, juntamente com as imagens de família entendidas 
como práticas sociais e culturais, verificamos são elas mesmas que nos vêm retratar as mudanças já ocorridas no imaginário social em relação às imagens de família. Estas dão-se a ler, compreender (ou vender?) pela circulação de seus carros como verdadeiros espaços publicitários da sua constituição e identidade cultural.

Há uma abordagem teórica diferente da nossa que colabora, porém, para compreensões mais macroestruturais, demonstrando como novas práticas culturais se vão tornando ritualísticas e configuram modos de ser e estar em sociedade. Isto dá-se na perspetiva de oportunizarem o manejo de signos e a produção de sentidos gerando, assim, atitudes económico-políticas. Neste sentido, importa citar Silva, Galhardo e Torres, especialmente quando afirmam que:

Toda a cultura tem os seus rituais e são estas práticas que inserem os indivíduos numa determinada religião, comunidade, sociedade ou, em termos mais específicos, num determinado código simbólico. Na sociedade contemporânea, podem considerar-se rituais os comportamentos e ações que estruturam uma dinâmica social comum e que comunicam com o sistema de significação a que pertencem os indivíduos. Pertencem ao domínio da comunicação, porque comportam a manipulação de signos e a construção de significados. (Silva, Galhardo \& Torres, 2011, p. 304)

\section{CONSIDERAÇÕES FINAIS}

Os autocolantes, como produtos da indústria cultural, das tecnologias da comunicação visual podem se tratados, em nosso entendimento, a favor da educação, pois trazem sentidos diversos e uma rica contribuição de aprendizagens possíveis. Ou seja, as narrativas dessa cultura urbana, trazidas ao estudo e ao debate no campo educacional como abordagem pertinente aos espaços educativos pode ajudar aos professores, às escolas e à educação, de uma maneira geral, a reconhecer-se e a reconhecer o outro como legítimo em sua cultura, percebendo a sua influência nas relações escolares. Além disso, podem ampliar os cenários de referências que se dão na interação de "aprendentes" com a visualidade das imagens urbanas e os seus sentidos.

A fabricação de tais autocolantes e demais produtos da comunicação visual é certamente feita de forma consequente à leitura da sociedade para a qual se destinam. Afinal, emerge da mesma sociedade o desejo e a necessidade de pertença ao imaginário de uma "família feliz". E, como já afirmamos, o estudo dessas narrativas e dos sentidos que seus autores lhes atribuem permite intuirmos acerca dos processos de desagregação, de novas "incorporações" e reajustes por que passa a instituição familiar na atualidade, e compreendermos, assim, um pouco mais da cultura desse humano que hoje vem à escola.

Em décadas anteriores, quer parecer-nos, a iniciativa de exaltar a dissolução da conservadora constituição nuclear da família convertia-se numa forma de valorização de formas alternativas de vida e de convivência. Conversando com adeptos e não adeptos dos autocolantes da 'família feliz', podemos dizer que há na intenção de mostrar a sua 
"imagem de família" uma atribuição de valores, não somente aos conservadores, mas, e sobretudo, àqueles novos que reafirmam a família como sendo constituída a partir também de laços culturais e não somente parentais.

Ao focarmos as nossas discussões nesses autocolantes retirando-os da banalidade, da plenitude da imagem, pensamos continuar a conduzir o debate em torno da pluralidade dos desenhos de família abundantes na contemporaneidade. Assumimos, desta maneira, a crítica à ausência de um cuidado maior nas relações escolares que poderiam explorar as manifestações e narrativas do contexto urbano, encontrando outros sentidos para a compreensão dos estudantes e suas famílias, destacando a complexidade relacional na nossa cultura, mobilizadora de aprendizagens na diversidade.

\section{REFERÊNCIAS}

Araújo, E. R. (2004). A mobilidade como objecto sociológico. Acedido em https://repositorium.sdum.uminho. pt/bitstream/1822/3913/1/A\%20Mobilidade\%20como\%20objecto\%20sociologico.pdf.

Bachelard, G. (1994). O direito de sonhar. Rio de Janeiro: Bertrand Brasil.

Barthes, R. (2008). Análise estrutural da narrativa. Trad. Maria Zélia Barbosa Pinto. Petrópolis, RJ: Vozes.

Bauman, Z. (1998). O mal-estar da pós-modernidade. Trad. Mauro Gama \& Cláudia Martinelli Gama. Rio de Janeiro: Jorge Zahar.

Bauman, Z. (2009). Confiança e medo na cidade. Trad. Eliana Aguiar. São Paulo: Jorge Zahar.

Bosi, E. (1994). Memória e sociedade: lembranças de velhos. $3^{\text {a }}$ ed. São Paulo: Companhia das Letras.

Bretas, B. (2006). Interações cotidianas. In C. Guimarães \& V. França, Na Mídia, na Rua: Narrativas do Cotidiano (pp. 24-42). Belo Horizonte: Autêntica.

Colomer, T. (2001, dezembro). La enseñanza de la literatura como construcción de sentido. Lectura y Vida Revista Latinoamericana de Lectura, 22, 6-23.

Delory-momberger, C. (2008). Biografia e educação: figuras do indivíduo-projeto. Trad. Maria da Conceição Passegi; João G. da Silva Neto \& Luis Passegi. São Paulo: Paulus; Natal: EDUFRN.

Derrida, J. (2001). Mal de arquivo: uma impressão freudiana. Trad. Claudia de Moraes Rego. Rio de Janeiro: Relume Dumará.

Echeverría, R. (2006). Ontologia del linguaje. Buenos Aires: Granica.

Foucault, M. (1992). O que é um autor? Lisboa: Passagend/Vega.

Gil, A. C. (1999). Métodos e técnicas de pesquisa social. São Paulo: Atlas.

Guimarães, C. \& França, V. (2006). Experimentando as narrativas do cotidiano. In C. Guimarães \& V. França, Na Mídia, na Rua: Narrativas do Cotidiano. (pp. 86 -102). Belo Horizonte: Autêntica.

Hall, S. (2006). A identidade cultural na pós-modernidade. Trad. Tomaz Tadeu da Silva \& Guacira Lopes Louro. $11^{\text {a }}$ ed. Rio de Janeiro: DP\&A.

Larrosa, J. (1995). Dejame que te cuente. Ensayos sobre narrativa y educación. Barcelona: Laertes. 
Larrosa, J. (2006). Pedagogia profana: Danças, piruetas e mascaradas. Trad. de Alfredo Veiga-Neto. Belo Horizonte: Autêntica.

Lakatos, E. M. \& Marconi, M. A. (1988). Fundamentos de metodologia cientifica. São Paulo: Atlas.

Le Breton, D. (2009). As paixões ordinárias: antropologia das emoções. Trad. Luis Alberto Salton Peretti. Petrópolis: Vozes.

Leite, N. V. de A. (2009). Transmissão da experiência: o estranho na narrativa. Estudos interdisciplinares psicanálise e cultura. São Paulo: UNICAMP. Acedido em http://www.uva.br/trivium/edicaor/artigostematicos/7-transmissao-da-experiencia-o-estranho-na-narrativa.pdf

Maffesoli, M. (1995). A contemplação do mundo. Porto Alegre: Artes e Ofícios.

Maffesoli, M. (1998). Elogio da razão sensível. Trad. Albert Christophe Stuckenbruck. Petrópolis: Vozes.

Maffesoli, M. (2001, agosto). O imaginário é uma realidade. FAMECOS: Mídia, Cultura e Tecnologia, 15, 74-82.

Maffesoli, M. (2005). O mistério da conjunção: ensaios sobre comunicação, corpo e socialidade. Trad. Juremir Machado da Silva. Porto Alegre: Sulina.

Maffesoli, M. (2006). O tempo das tribos: O declínio do individualismo nas sociedades pós-modernas. $4^{\text {a }}$ ed. Rio de Janeiro: Forense Universitária.

Maturana, H. (2002). Emoções e linguagem na educação e na política. Belo Horizonte: UFMG.

Maturana, H. (2001). Cognição, ciência e vida cotidiana. Belo Horizonte: UFMG.

Delory-Momberger, C. (2008). Biografia e educação: Figuras do indivíduo-projeto. Trad. Maria da Conceição Passeggi; João Gomes da Silva Neto \& Luís Passeggi. Natal: EDURFRN. São Paulo: Paulus.

Pastana, D.R. (2005). Cultura do medo e democracia: um paradoxo brasileiro. Mediações - Revista de Ciências Sociais, 10, 183-198. doi: 10.5433/2176-6665.2005v10n2p183

Queiroz, I. S. \& Lacerda, N. (2005). Do espaço urbano sob a égide do medo à cidade que medra: representações sociais e práticas cotidianas num ambiente marcado pelo medo da violência urbana. XI Encontro Nacional de Pós-Graduação e Pesquisa em Planejamento Urbano e Regional - ANPUR (pp. 1-20). Salvado: Bahia.

Silva, S; Galhardo, A. \& Torres R. (2011). O ritual da comunicação e o ritual do consumo: novas tribos, novos rituais. Revista Comunicação e Sociedade, 19, 301-315. doi: 10.17231/comsoc.19(2011).913.

Silva, J. M. da. (2004/dezembro). Interfaces: Michel Maffesoli, teórico da Comunicação. Revista FAMECOS: Mídia, Cultura e Tecnologia, 25, 42-48

Sodré, M. (1988). A literatura de mercado. Série Princípios. São Paulo: Ática.

Tomás J. C. de S. P. (2010). A invisibilidade como subversão pós-moderna na cultura urbana. Revista Comunicação e Sociedade, 18, 165-171. doi: 10.17231/comsoc.18(2010).995.

\section{NotAS BIOGRÁFICAS}

Felipe Gustsack possui graduação em Letras Português Inglês e Literaturas pela Universidade Federal de Santa Catarina (1988), mestrado em Educação pela Universidade 
Federal do Rio Grande do Sul (1998) e doutorado em Educação pela Universidade Federal do Rio Grande do Sul (2003). É professor do PPGEdu - Mestrado em Educação da Universidade de Santa Cruz do Sul - RS, vinculado ao Departamento de Educação.

E-mail:fegus@unisc.br

Universidade de Santa Cruz do Sul - UNISC, Rio Grande do Sul - RS, Brasil

Sandra Maria de Castro Rocha possui graduação em Letras-Português pela Faculdade de Filosofia Ciências e Letras Imaculada Conceição (1986), É pós Graduada em Letras pela UFSM (1988). Pós Graduada em Informática Educativa (2000), Mestre em Educação pela Universidade de Santa Cruz do Sul (2011). É professora no NTEM - Núcleo de Tecnologia Educacional da Prefeitura Municipal de Santa Maria e professora colaboradora no Núcleo Palotino de Estudos do Envelhecimento - NUPEN, na Faculdade Palotina de Santa Maria - FAPAS/RS, Brasil.

E-mail: manacroch@gmail.com

Universidade de Santa Cruz do Sul - UNISC, Rio Grande do Sul - RS, Brasil

* Submetido em: 10-04-2015

* Aceite em: 02-07-2015 